\title{
Visual Media and Communication: A Conundrum of Gender Disparity in Animated World
}

\author{
Bharti Magotra $^{1}$, Simran Preet Kaur ${ }^{2 *}$ \\ ${ }^{1}$ Research Student, SMVD University \\ ${ }^{2}$ Assistant Professor, SMVD University
}

*Corresponding Author: Simran Preet Kaur, Assistant Professor, SMVD University, India

\begin{abstract}
The verbal and visual mediums play a cardinal role in internalization of gender stereotypes in children. Being an influential form of communication, the media has an indispensable impact on the child's psyche. Besides being a mode of a method of entertainment only for youngsters, it has scholastic and socializing perspectives. Cartoon series as one such visual have provided youngsters characters displaying behaviours and individual traits that they imbibe and internalize, thereby promoting stereotypical expectations. Gender bias in the cartoons is formulated by the stereotypes which are associated with the roles expected to be performed by a girl or boy. Gender disparity in cartoons reflects women characters as weak or inferior, bound to the household chores and male as strong or superior. Keeping in cue with the aforesaid, the research examines gender disparity prevalent in animated world and to reveal its adverse impact. The research analyzes two contemporary Indian cartoon series from the perspective of the character's physical appearance, male/female roles in problem-solving, social roles and behaviour.
\end{abstract}

Keywords: Gender, Stereotype, Animation, Children, Media.

\section{INTRODUCTION}

Visual narration being an important mode of communication has been rapidly spreading all over the country and is "the most pervasive and one of the most powerful" (Wood, 2014: 3).Children start watching television at the very early stage of their life. They become eager watchers as soon as they reach2 to 4 years of age. In light of this fact, an excessive number of youngsters are watching television excessively and the cartoons that they watch have turned out to be an addiction. Children distinguish promptly with cartoon characters, such characters can be sure good examples that empower good conduct among children. Krish, for instance, always helps people of his surroundings. On the other side, there can be bad character that provides no moral lesson to children like Kidmara. Cartoons play an essential part in framing children's perception about male and female. They observe the behaviour and action of the characters and try to copy them. Being susceptible to gender stereotypes that are portrayed on television, particularly in cartoon series, they reinforce those accepted behavior shown through media, in their lives. Likewise, in an article by Arma (2010), "The effect of cartoon movies on children's gender development", the focus is on pros and cons of animated series and the roles that are ascribed to cartoons. The paper claims that the cartoon movies are not limited to entertainment purposes but they involve socializing aspects, gender stereotyping being one of them. Further, Arma also highlights that characters in the movies can be both human and nonhuman or living or non-living objects. Non-living and non-human characters show human highlights, for example, they can talk, walk simply like people. These types of characters are important in the movies because of their human like features. In some cartoons, lifeless and animal characters play stereotypical female or male roles. In some cartoon movies, sex reassignment takes place wherein a female character disguises as male or vice-a-versa intrigued with magical realism. Likewise, in cartoon movies sex transformation also takes place which often creates uneasiness or nervousness among children. Children have no sense of understanding; they don't realize that there exists a remarkable gap between reality and fantasy. Such kind of transformations in cartoon series affects the psyche of the child and its development. So, gender disparity is clearly reflected through the characters roles. In cue with this, the research paper not only reveals inequity prevailing in animated world but also seeks for a solution to neutralize them. 


\section{TELEVISION AND ITS IMPACT ON INDIVIDUAL'S BEHAVIOUR}

In television the characters communicate with one another and children often adopt their way of communication. The way these cartoon characters communicate with each other influences the behaviour of children. They try to copy their manners and behaviour. In the similar vein, a report on "What media teach kids about gender" by Caroline Knorr (2017) highlights how children start imbibing specific traits of being strong or fearful, as she avers, "'strong and brave' superhero becomes aggressive and hostile. That 'fearful and meek' princess becomes submissive and weak". In the light of the above argument, one can trace such reflections in research done previously, like Hassan and Daniyal(2013) in "Cartoon network and its impact on behaviour of school going children: a case study of Bahawalpur, Pakistan" focuses upon the effect of cartoon on the behaviour and manners of the youngsters. They talk about impact of Cartoon Network which standout among the most loved cartoon channel; it runs 24 hours and children invest the greater part of their relaxation time before it. Cartoons do not only pull children towards them through via its substance rather they teach positive as well as negative propensities. The authors lay emphasis on the fundamental grounds that have adverse impact on children who watch cartoons which reflect the themes of violence or brutality. The paper explores the adverse effect of harsh content presented in cartoon on the behaviour of children and how children not only mimic or copy their favourite cartoons but also compel their parents to get them cartoon costumes, accessories and toys. Cartoons have an iron hold on psyche of children, both mentally and physically. They identify themselves with their favourite characters. They behave as a cartoon, their choices, likes, dislikes, way of dressing, everything is influenced by cartoon. The paper impinges upon how the language used by children is a result of watching cartoons. There are many harsh and bad words used in cartoons which are quickly picked up by children. Hassan and Daniyal say that children mostly prefer watching comedy cartoons as compared to action. Ostensibly, violence and brutality are prominent traits in kids' shows. In comic cartoon shows, the battle between celluloid characters is enjoyed by children. This can be clearly evidenced through the popularity of worldwide famous cartoon Tom and Jerry. Further, a lifetime of viewing stereotypical media becomes so ingrained, it can ultimately affect kids' career choices, self-worth, relationships, and ability to achieve their full potential (Knorr,2017).Further, critics like Nathanson (2002) in Counteracting the Effects of Female Stereotypes on Television via Active Mediation, Huntemann and Morgan (2001) in "Mass Media and Identity Development" have also claimed how children modify their attitude by watching such cartoon series. Permanent and consistent exposure to such shows not only cultivates in children a set of "values, beliefs, dreams and expectations, which shape the adult identity a child, will carry and modify throughout his/her life" but also assists in reinforcement of gender stereotypes.

Having taken a cognizance of this, children literature became a vibrant area of research. Fairytales considered as 'classics' were re-read to expose the gender ideology that was perpetuated in them. Patricia Mathew and Jonathan Greenberg (2009) in "The Ideology of the Mermaid: Children's Literature in the Intro to Theory Course" also emphasize upon reinforcement of stereotypes through continuous watching as they highlight, "students encounter these children's texts during the very time of life when they are unconsciously absorbing ideological codes, their emotional investment in the ideological legitimacy of such texts is so high that these texts appear, ironically to be uniquely free of ideology." Thus the embedded gender ideology remained invisible for quite some time. Children animation produced largely by Disney was mostly based on these fairytales and fared no better when analyzed for the biased representation of gender.

\section{REVIEW OF LITERATURE}

The book titled "Encyclopedia of gender in media" exposes the impact of the media in shaping gender. Since the mid-1960s, enlivened cartoon shows have been a prevailing kind of visual programming on television. With regards to more extensive worries about the media focusing on youngsters, scholars working on media and gender have concentrated on fierce and violence substance and advancement of consumerism in cartoon shows. The historical backdrop of broad communications both behind the scene and before camera has been a history marked by avoidance of women. In terms of media, females have exercised restricted roles especially in television and "are often stereotyped and sexualized when they are depicted in popular content" (Smith, Choueiti \& Pieper, 2014). Media as an operator of socialization, enormously affects how we understand the world around us as "Gender roles, ... exist solely because society as a whole chooses to accept them, but they are perpetuated by the media" (Lantange, 2014).Media whether as content or innovation mediate 
our connection to social organization that structures our lives, including education and health care. Media content additionally shapes our gender identity and self character. Gender is outlined as a socially built arrangement of characterization that relies on the parallel classes of femininity and masculinity. Media representations contain veiled and explicit scripts pertaining to gender. The stories shown on television encourages gathering of people with respect to social roles and individual characteristics that are approved for male and female. For instance women probably appear in television and film as mother and guardian in contrast with male. Despite the fact that this is organic truth that females give birth to children; this gendered television content replicates the thought that women are naturally better at raising babies. It is seen from the principle two channels of cartoon, Nickelodeon and Cartoon Network that paying little heed to whether male or female as lead, savagery stays predominant in children, shows. Brutal, violent and harsh content which is shown in media has potential impact on youth and this subject matter has been a focal point of the media. Numerous courageous women are presently set apart as a major aspect of "Disney Princess Franchise", which incorporates champions from contemporary and classical movies; Ariel, Belle, Snow White, Jasmine, Cinderella, Princess Aurora, Mulan and Tiana among them. In traditional Disney movies, Disney princess were most importantly delightful and youthful, fragile and beautiful and they shared with each other sweetness, innocence and loving, nurturing and caring nature as key similarity which maintains their balance with their stepmother, malevolent rulers and different villainess who try to wreck them. In this way, Disney World projects parallel resistance constructing women as young, sweet, innocent, beautiful, loving, caring, fragile and great or vain, evil, mean, wicked, ugly and old.

\section{Methodology}

A succinct overview of literature survey highlights that research on gender as a theme has received wide attention "in the work of linguists, sociolinguists, historians, women studies experts, and social scientists" (Amitabh 16). But very less research has been done on the prevalence of gender inequity in Indian cartoon series. Keeping in cue with the aforesaid, two cartoon series, Chhota Bheem and Kumbh Karan, have been considered for the analysis in this research paper. These cartoon series selected appear at a few times amid the day, and are extremely available to a youthful gathering of people. They have people as the hero rather talking objects or animals, for example, PCs, autos, robots and other such manifestations. Further, from the perspective of its impact upon spectators and the behavioural pattern of spectator cultivation and social learning theory have been taken for theoretical analysis.

There are many theories regarding the media's influence on individual psyche which talk about the impact of the media like cultivation theory and social learning theory. Critics like Gerbner have highlighted that television is "an integral aspect of a dynamic process" that reestablishes beliefs and opinion" and likewise "become a powerful and influential common source for learning, for teaching children about norms and values in society, and constructing a social reality" (pp. 180). The media exorcises the mindset of the general public through its dual nature; which can be either positive or negative. The media is credited with the ability to create culture and new trends and it is often referred as "Mediated culture" by many sociologists such as Andre Jansson and Thomas de Zengotita. Among various forms of the mass media, television is the most influential medium which reveals social reality and its internalization has an impact on our psyche. Being a systematic way of telling stories; it brings all the trends, happenings of the world at one place. Television has become an efficient medium of information and it holds an important place in the socialization of children. Children are innocent beings who have no sense of understanding and television, being a significant part of their life, disrupts the distinction between reality and fiction making them believes what is shown in the television is social reality. Television differs from other forms of media on the basis of its visual and imagery representation. Visual media holds a long-lasting impact on the psyche of the people as compared to verbal media. Likewise, critics like George Gerbner have also examined the long-lasting effect of television on people in his "cultivation theory". Gerbner claims that the additional time individuals spend sitting in front of the TV, the more they have confidence in the truth which is shown in television. People perceive it as the social reality unaware of the fact that it is merely fictional. The visual representation of objects and characters is disseminated through television which influences the acuity of true world. Gerbner suggest that television viewed at young age can alter the social reality beliefs. He avers that television internalizes those values which are already bestowed in culture. It is distinguished between two by cultivation theorists: 'first order' effect and 'second order' effects. First 
order effects include views, faith, and truth like rife of violence about the world whereas second order effects includes attitude towards judiciary, law, rules or orders. He has also divided viewers in two groups: heavy viewers and light viewers. Heavy viewers are those people who are more into television and witness world according to the ways in which it is depicted on television.

Social learning theory suggests that children mimic and inculcate the behavioural pattern that they observe in their ambience and similarly the one they observe on television. The most influential psychologist Albert Bandura gave the notion of social cognitive theory (SCT) and was also responsible for putting forth Bobo doll experiment. Albert Bandura has discussed in his cognitive theory that children watch and copy activities of the general population around them in his theory. A fundamental assertion of SCT is that individuals learn through their own particular encounters, as well as by watching the activities of others and the aftereffects of those activities is seen in the behavior of children. SCT is the basis of the movement which is against brutality and violence in the media. Albert Bandura has also talked about observational theory which is a part of social learning where an individual learns by observing the behaviours and actives of others. This theory requires a model, for example kin, companion, parent, friend, or instructor with environment. During the phrase of childhood, model plays an important role and holds a higher authority. Infant tries to copy the model and acts in the ways and manners of the model. In social cognitive theory of personality, Bandura incorporated the idea of observational learning as one of the prime focus. Walter Mischel, a personality researcher, has given a noteworthy gift to the development of SLT. Mischel has built up a definite program for the investigation of individual factors, while supporting an extensive variety of SLT ideas. The Indian scenario, however, is quite different. The children's literature in general and animation in particular has not been able to attract the attention of the scholars. Hence the present endeavours. Moreover, I do not claim to represent the Indian scenario as I analyze only the cartoons and children in the Hindi language. The method here applied is that of data interpretation where in male female characters in the specific cartoon movies were analyzed in cue with what Berger (1991) highlights as "a research technique that is based on measuring the amount of something in a representative sampling of some mass-mediated popular art form" (p.25).

\subsection{Research Questions}

The research hinges on the following research questions and seeks to develop an understanding of the following:

- How are the social roles and behaviour pattern influential in promoting gender studies?

- Is gender disparity visible in cartoon series or not?

- How can communication play a key role in neutralizing gender disparity?

- How is physical appearance gendered?

\section{GENDER INEQUITY}

Discussed here is the gender inequity and the Animated World: A Reflection into Chhota Bheem and Kumbh Karan.

A survey of the children's magazines in Hindi crops up names like Chandamama, Champak, Nandan and Parag which are all widely reputed. However, an analysis of their contents and conceptual framework reveals the deeply embedded gender stereotypes in Chandamama and Champak borrow from the Panchtantra and Jatak stories. Nandan has a potful of stories about fairies and other characters from the realm of magic. Parag has secular stories, which nevertheless, are deeply embedded in the Indian social ethos. Needless to say that due to their basic conceptualization, they cannot escape the gender bias inherent in the Indian ethos and culture which dictates their representations of gender and re-inscription of gender stereotypes as sanctioned by the society at large.

If we come to children's animation in India, it is heartening to see that in the recent years many indigenous cartoon series have been launched prior to this we have a whole generation fed by Heman, Spiderman, Superman and the other series which were exclusively produced in the west. However, a review of the indigenous cartoon series reveals that most of them are mythological in their character like Bal-Hanuman, Bal-Ganesha, Krishna AurBalram, Roll No. 21 (based on the 
modernization of the Krishna-Kans story) and the list goes on and on. I do not deny that these are an effective way of acquainting our children with our mythology. But what about the gender stereotyping inherent in the mythology? The representation of women in these series does not in any way deviate from the norm. As explicated by Signorelli in his cultivation theory, the continuous exposure to such traditional roles in animated world modifies the perception of children thereby, contributing in the conception of social reality. The only secular cartoon series on the Indian television are ChhotaBheem and Kumbhaur Karan, the former being a current rage with children. An analysis of the representation of female characters in these two would reveal the current pattern of gender representation in children's animation.

Researchers like Kelly have put forth four different types of cartoon characters; the hegemonic male, the submissive or the inadequate male, the fragile female and the modern female. The stereotypically robust males are generally the protagonist and are also the conflict resolvers. Bheem, Kumbh and Karan can easily be recognized as fitting in this category. Masculine man is one who attributes manly traits who fits in the culture's cliché. Man with good looks muscles and moderate attire and hairstyle. Conversely, the insufficient and submissive male has an inadequate bodily structure, contrary to the hegemonic one who is physically strong. The inadequate male is represented as frail, frightful fearful, weak and lack courage and consequently is the reason for conflict. Moreover, if they resolve any solution, they do it in a comical manner. Kalia, Kichak, Dholu and Molu easily fit this category. Likewise, the fragile and innocent females are similar to the inadequate males. Their attire is in such a way that it restricts them from performing any male task. Chutki, Indumati and Tara easily fit the description modern females as they are not as delicate and conversely yield more in resolving complicated matters than the delicate females. The only character who fits in this category is Chutkhi.

According to Calvert, (1999) the villains in the cartoon characters are also most-often than not males. Mostly in cartoons, the dynamics between hero and anti-hero dominate the whole plot; delimiting the females to side roles or supporting ones. Women in the cartoon are not given an equal platform as compared to men. Their roles remain passive in this process where in they are often portrayed as atypical heroines. Mostly they are shown as damsel in distress where they are always in some kind of conflict and their conflict is resolved by the hero. One of the most consistent problem, which arises conflict is kidnapping of the heroine where their starts a battle between the protagonist and antagonist. The fight focuses on the hero and villain which overshadow the role of heroine. By the end, heroine is being rescued by the hero and it shows women as weak and incapable of protecting themselves and their dependency upon man. Hero wins over villain as in ChhotaBheem, Indumati and Chutki are often saved by Bheem.

An analysis of the characters of Indumati, Chutki and Tara reveals that the ratio of the male and female characters is 3:1 and ChhotaBheem and 2:1 in Kumbh and Karan. In each episode it is being witnessed that the number of male members are more than females. The average percentage of male is $70 \%$ and female is $30 \%$ only. Thompson and Zerbinos in "Gender roles in animated cartoons: Has the picture changed in 20 years?"examined that in cartoon series "the number of males among protagonists is more than females by one third while the numbers of other male characters are nearly one fifth more than females."(Thompson \&Zerbinos, 651-673).The unequal ratio of both the sexes in cartoons series denotes how women are given less importance and prominence as compared to men. Throughout the series there is not even a single episode where female ratio exceeds male. In all the episodes it is been analyzed that the presence of male characters always overshadow the female character. Therefore, it is mostly boy's world that children view in these cartoon series. Streicher's (1974) study is one of the earliest references used by the researcher to review the literature on representation of gender in children's television programming. She conducted a 9-week study in 1972 and reported that male characters outnumbered female characters in an overwhelming manner across all genres of programming.

Table1. Projection of male female ratio in Chhota Bheem and Kumbh Karan

\begin{tabular}{|l|c|c|}
\hline \multicolumn{1}{|c|}{ Cartoon Series } & No. of Males & No. of Females \\
\hline ChotaBheem & 5 & 2 \\
\hline Kumbh Karan & 3 & 2 \\
\hline
\end{tabular}




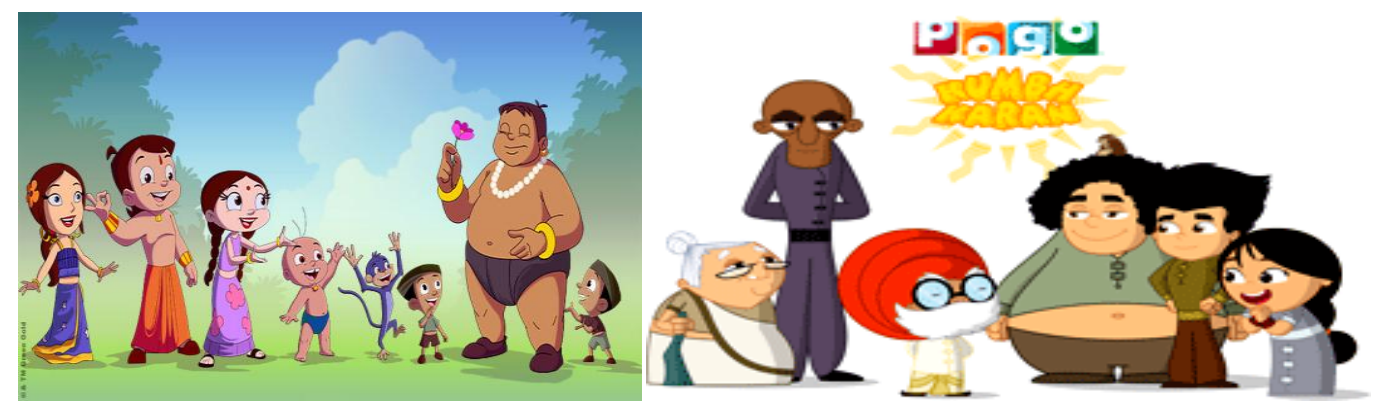

Fig1. Male female ratio in the Cartoon Series Chhota Bheem and Kumbh Karan

Chhota Bheem is the most popular cartoon in India and is telecast a number of times. The story revolves around a young boy depicting the tales and experiences of the eponymous character. The setting of this series is rural in its context and the village where all the tales of Bheem take place is a fictional kingdom named Dholakpur. The main characters of the series are Bheem, Raju, Indumati, Chhota Bheem, Chutki, Jaggu, Dholu, Kalia and Bholu. It is always the protagonist in cartoon series who is very powerful and saves his friends and his village from the problems. Bheem has a big heart who always helps other and is known for his strength. He is often called up by the king for seeking suggestions. The character Bheem is taken from the epic Mahabharata and the name itself suggests power, strength, energy, muscularity whereas the main female character is named as Chutki which suggest something which is very timid and small. The names given to the characters themselves show the gender disparity in the cartoon series. Chutki is 7 year old girl who is a close friend of Bheem. She often assists him in all his adventures but her role always remains passive. She always feels happy on the victories of Bheem. Chutki is stereotypical girl who looks after her household chores in the absence of her mother. She is seen as a typical girl who gets possessive about her boyfriend. In many episodes she gets jealous whenever Bheem gets close to other girls. Her jealously reveals the fact that she has a soft corner for Bheem. She is like normal girls who want their Mr. Perfect and she considers Bheem as her Mr. Right. Another pertinent observation is that in Chhota Bheem none of the male characters are given any parental figures to exercise patriarchal control over them. Neither Bheem, nor Kalia, nor Dholu-Molu are given a set of parents. Raju's father is hinted at but he is a soldier who is always away on war or missions for the king. Chutkhi and Indumati, however, are not left free. Chutkhi is given a mother who looms large over her and makes the ladoos that Chutkhi feeds Bheem (fulfilling the traditional role of Annapurna) that are a source of his strength. Indumati is the daughter of the king of Dholakpur. A princess, she is typically portrayed as the delicate female. Both Chutkhi and Indumati are dressed in skirts and blouses which are mostly pink or lavender in shade. Both have long hair typically tied in a single are two ponies. Both these characters do not in any pronounced way deviate from the qualities that are claimed to be feminine.

'Just as' consistent with cultural views of gender are depictions of women as sex objects who are usually young, thin beautiful, passive, dependent, and often incompetent and dumb"(Wood,2014:2). Indumati, as princess, is presented as a complete embodiment of these qualities. She is very delicate soft spoken, always by her father's side, obedient and to a large extent passive. She might be a part of the conflict, but never of conflict-resolution.

Chutki cannot escape the connotation of 'Annapurna', she is not delicate as Indumati. She is the integral member of the Bheem's gang and participates in all the adventures undertaken by the group. She is not passive like Indumati. She also gives inputs that help in conflict resolution. However, she is never the direct cause of conflict-resolution-the responsibility being that of Bheem solely. Moreover, her place is firmly secured as being second to Bheem. Moreover, when Bheem goes for any activities like archery competition or wrestling, that are essentially considered as male domains, Chutkhi is relegated to the periphery and it is Raju that becomes a befitting companion to Bheem. The qualities that Chutkhi is mostly praised for by the group are mostly kind-heartedness and generosity and sometimes even intelligence but never valour that is exclusively the domain of men. Moreover, the fact that Chutkhi is not given a proper name. Even the monkey in the series is named Jaggu but Chutkhi is just Chutkhi. Gender disparity is fore mostly shown in many of the episodes, one of them is named as "Mother's Day Special" where Chutki wants to do something special for her mother. She brings flowers for her like a sweet daughter and decides that on Mother's Day she will give full rest to her mother and will take care of everything by herself. Bheem and her other friends also assist her 
which often shows her incapability of doing everything by herself. She cleans the entire house and makesladoos for her mother's sweet stall. Though she does the entire household and kitchen work and others did the work which required physical strength like milking the cow, electrical work and going to the market for selling of ladoos. The females in the cartoons are shown as unskilled who are engaged in unnecessarily activities like Chutki loves playing with dolls whereas Bheem is always into some kind of trouble solving mission. In most of the episode the role of Chutki is limited to feel happy and pay applauds for the achievements and victories of Bheem. She is not given any prominent importance in the series. Her representation in cartoons show how children perceive the role of women as less efficient and passive and male as efficient and active. Boys often identify themselves as Chota Bheem and girls as Chutki.

Further, Tara in Kumbh Karan is more allied to Indumati than Chutkhi. Flanked by two male characters, there is no room for her to be active self-spoken, delicate and kind hearted, she most often than nor acts as a harmonizer and pacifier between Kumbh and Karan. She does accompany the boys in their adventures, but mostly like Indumati is a cause of conflict, but never conflict resolution. If at all she gives any input towards the resolution, it is negligible. Being a girl she also lends a hand to dadi (Grandmother) in cooking.

Thus the analysis of the female characters in the children's animation on the Indian silver screen reveals that all of them are drawn within the firm bounds of the patriarchal set up. Stereotypical, they cannot escape their gender. Chutkhi does represent the modern female but strictly within the norms of patriarchy. Moreover, she is not the princess. In the similar vein, critics like Cohen highlight that characters in media and cartoon shows identify themselves with the characters and start imbibing their values and behaviour. For instance, girls pretend to be princess, wear such attires whereas boys pretend to be action heroes safeguarding the damsels in distress. The plight of Indumati is even worse. Though a princess, her father does not even consider her as the inheritor of the crown. He firmly convinced that after him, it is Bheem who shall inherit the throne. The any hint of female character assuming a position of power is firmly rooted out.

\section{GENDER BIAS}

Gender bias is prevalent in every sphere of society. The roles performed by the characters are assigned according to the roles that are prescribed by society which are considered appropriate for both the genders. Gender roles are in certainty doled out by society, prompting attributed social generalizations. Gender roles are dictated by the social convictions about what the gender roles ought to be. Coon and Mitterer (2010) define gender role stereotypes as 'oversimplified and widely held beliefs about the basic characteristics of men and women' (p.365). It starts with the process of socialization itself where prejudice is seen on the basis of gender. Girls are expected to be angels of the house and boys are free to do things according to their freewill. The gender disparity is even seen in the selection of toys for both the sexes. The different treatment of both the sexes by the family is the initial point from where this gender disparity starts and children identify that they are different. By the 24 months of age, children's recognizes their gender and constructs a world of male and female. Commenting upon the impact of such unrealistic representations on children, Anaba (2016) in "Children's perceptions of gender roles as portrayed in Disney films" claims that such "representations of the ideal male and female figure are portrayed and young children often identify with these beloved characters, there by affecting the way that they conceive beliefs regarding their future roles in society" (p. 9).Family is the primary source from where gender biasness start. Secondary sources are schools, friends, media; media being the most influential one. In many cartoon movies one sex is shown as dominant i.e. men and another as submissive i.e. women. Children assimilate and internalize these roles that show large discrepancies between prominence and portrayal of male and female characters. Further, if female characters are involved in jobs, they are dominated by males or are projected as dumb characters, as 'beauty without brains'. Such stereotypical connotations assist in performing gender stereotyping. Males are shown as strong, skilled, powerful, intelligent whereas women as fragile, weak, non-intellectual and submissive.

\section{Parental Role}

Parent plays a vital role in child's mental and physical growth through the medium of their guidance, behavior and the sources they provide to them like toys, television, video games etc. Child learns about the male dominance over female when they witness their father's dominance over their mother. 
The same culture of dominance of male over female gets validated when children witness the same in cartoon series. In most episodes of Chhota Bheem and Kumbh Karan, it is shown that male members always overshadow the female with respect to their sex ratio, physical characteristics i.e. males are shown as powerful, strong whereas women as weak, fragile and their ability in problem solving. This problem persists in most of the cartoon series. Since, children are more tempted to watch cartoon than doing any other activity, parents uses cartoons as a tool to make their kids busy and to free themselves to do their own stuff. Hence they encourage their children to watch cartoons frequently. Parents fail to give their children required amount of time due to increasing demands from their professional life. Therefore, this situation results in lack of communication between parent and children. Children do not get required attention of their parents and they end up spending more of time watching cartoon. Children built perceptions about real life watching cartoons which often promoting gender stereotype.

\section{CONCLUSION}

Numerous television programmes screened every day project gender experiences, communicating gender discrimination which is a social issue. A child begins to recognize differences of sex from seven months onwards. But this sensitization regarding one's own gender with ensuring gender-roles and gender appropriate behaviour comes by the age of seven. During this time everything from the behaviour of the parents, to school environment, to peers, to toys, to the socio-cultural set up mould child's gender perception, the media being most powerful of all. Everything about the world and society is being communicated to him by his parents but now a days, media too plays a prominent role in the socialization. Even reality shows project gender biasness where in females are treated as an object of ridicule. As Amitabh V. Dwivedi in "Rape in the Metropolis" highlights how reality show like Big Boss 7 is an example of female abuse where in one of the participant "abused every single woman in the house" (Dwivedi, 2014:7). Gender bias being a prominent issue is exclusively found in the entire media where in male characters hold the centre and females are at periphery. But when one delves into its root cause, it starts from infancy, when the child is at the growing phase of his life. Gender bias in children shows is dismal since it is unavoidable for children, who are unaware of the demarcation that exists between fantasy and reality. Therefore, the aim should be to neutralize gender roles so that child grows as an individual, as a human being rather than as male or female, "making themselves as an emblem of both the set of emotions" (Kaur, 2016: 288).

\section{REFERENCES}

[1] Bandura, A., \& Walters, R.H. (1963).Social Learning and Personality Development. New York: Holt, Rinehart \& Winston.

[2] Berger, Arthur Asa. (1991). Media Research Techniques. Newbury Park, CA: Sage.

[3] Calvert, S. (1999). Children's Journey through the Information Age. Boston: McGraw Hill.

[4] Chhota Bheem. Directed by Rajiv Chilaka. Green Gold Animations, (2008).Cartoon Series.

[5] Cohen, J. (2006). Audience identification with media characters. In J. Bryant \& P. Vorderer (Eds.). Psychology of Entertainment (pp. 183-197). Mahwah, New Jersey: Lawrence Erlbaum Associates, Inc.

[6] Anaba, Cynthia E. (2016). "Children's Perceptions of Gender roles as portrayed in Disney films". Submitted in partial fulfilment of the requirements of the BA Honours in Psychology at Dublin Business School, School of Arts, Dublin.

[7] Dwivedi, Amitabh V. (2014).“Rape in Metropolis: the Geography of Crime in Delhi”.Glocalism: Journal of Culture, Politics, and Innovation, 3,1-9.

[8] Dwivedi, Amitabh V. (2015).“GenderDiscrimination.”Encyclopedia of WorldPoverty. CA: Sage Publications, Inc. 2nded, 643-645.

[9] Eick, Kelly. May (1998). “Gender Stereotypes in Children's Television Cartoon”.Retrieved from https://www.calpoly.edu/ jrubba/495/paper1.html on 8 February 2018.

[10] Gerbner, G., \& Gross, L. (1972).“Living with television: The Violence Profile”.Journal of Communication, 26, 172-199.

[11] Gerbner, George. (1998). "Cultivation Analysis: An Overview”. Mass Communication \& Society, 1(3/4), 175-194.

[12] Gerbner, G., Gross, L., Morgan, M., Signorielli, N., \& Jackson-Beeck, M. (1979). “The Demonstration of Power: Violence Profile". Journal of Communication, 29.10,177-196.

[13] Gökçearslan, Arma an. (2010). "The Effect of Cartoon Movies on Children's Gender Development". Procedia Social and Behavioral Sciences, 2, 5202-5207. Science Direct. 
[14] Hassan, Ali., Muhammad, Daniyal. (2013). "Cartoon Network and its Impact on Behavior of School Going Children: A Case Study of Bahawalpur, Pakistan”. International Journal of Management, Economics and Social Sciences, 2.1, 6-11.

[15] Kaur,SimranPreet. (2017). "Blurring the Binaries, Blending the Gender: A Transition from Male Masculinity to Female Androgyny in Hindi Cinema". Media Watch: A journal of communication, 8(2),287-294.

[16] Kaur, Simran Preet. (2016) "Feminist Awakening in Bollywood: A Shift from Objectification to Subjectification" (Doctoral Thesis Awarded). Shri Mata Vaishno Devi University, Kakryal, Katra, J\&K, India.

[17] Knoor,C. (2017, June 19). Gender Stereotypes Are Messing with Your Kid. Retrieved from https://www. commonsensemedia.org/blog/gender-stereotypes-are-messing-with-your-kid\#

[18] Mathew,Patricia and Greenberg, Jonathan. (2009) “The Ideology of the Mermaid: Children's Literature in the Intro to Theory Course".

[19] Lantagne,A. (2014,July 15). Gender Roles in Media. Retrieved fromhttps://www.huffingtonpost.com/ Allison-lantagne/gender-roles-media_b_5326199.html

[20] Kumbh Karan. Directed by Silas Hickey, UttamPalSingh.Cornershop Animation, (2010).Cartoon Series.

[21] Nathanson, Amy I., Wilson, B.J., McGee, Jocelyn, \& Sebastian, Minu. (2002). "Counteracting the Effects of Female Stereotypes on Television via Active Mediation”. Journal of Communication, 52(4), 922-937.

[22] Smith L., Stacy; Choueiti, Marc; Pieper, Katherine (2014). “Gender bias without borders: An investigation of female characters in popular films across 11 countries” (PDF).Media, Diversity, \& Social Change Initiative.University of Southern California, Annenberg School for Communication \& Journalism.

[23] Streicher, H. W. (1974). "The Girls in the Cartoons”.Journal of Communication, 24(2), 125-129.

[24] Thompson, Teresa L. and Zebrinos, Eugenia. (1995). "Gender Roles in Animated Cartoons: Has the Picture Changed In 20 Years?”Sex Roles: A Journal of Research. 32: 651 - 674.

[25] Wood. Julia T.( 2014).Gendered Media: The Influence of Media on Views of Gender. NY U.Web.

Citation: Bharti Magotra, Simran Preet Kaur. "Visual Media and Communication: A Conundrum of Gender Disparity in Animated World". International Journal of Media, Journalism and Mass Communications (IJMJMC), vol 4, no. 1, 2018, pp. 44-52. doi:http://dx.doi.org/10. 20431/2455-0043.0401004

Copyright: (C) 2018 Authors. This is an open-access article distributed under the terms of the Creative Commons Attribution License, which permits unrestricted use, distribution, and reproduction in any medium, provided the original author and source are credited. 